\title{
The Effect of Glycerol/Water and Sorbitol/Water on the Plasticization of Hydroxyethylacryl Chitosan/Sodium Alginate Films
}

\author{
Pitchaya Treenate $^{1, a}$, Pathavuth Monvisade ${ }^{1}$, Masayuki Yamaguchi ${ }^{2}$ \\ ${ }^{1}$ Polymer Synthesis and Functional Materials Research Unit, Department of Chemistry, Faculty of Science, \\ King Mongkut's Institute of Technology Ladkrabang, Thailand \\ ${ }^{2}$ School of Materials Science, Japan Advanced Institute of Science and Technology, Japan
}

\begin{abstract}
This research aimed to investigate on the effects of glycerol/water and sorbitol/water on the plasticization of hydroxyethylacryl chitosan (HC)/sodium alginate (SA) films. The HC/SA films were prepared with different amount of glycerol or sorbitol as a plasticizer $(25,40$ and $50 \% \mathrm{w} / \mathrm{w})$ and kept at different relative humidity $(0 \% \mathrm{RH}$ and $50 \% \mathrm{RH})$ in order to restrict the content of water within the films. The results from differential scanning calorimetry (DSC) showed the miscibility of polymer and plasticizers (glycerol and sorbitol) for all blend compositions. A remarkable reduction of glass transition temperature $\left(\mathrm{T}_{\mathrm{g}}\right)$ could be obtained by adding glycerol over $40 \% \mathrm{w} / \mathrm{w}$. For sorbitol plasticized films, although the addition of sorbitol could reduce $\mathrm{T}_{\mathrm{g}}$, it was still higher than room temperature. It was claimed that glycerol could gain more effective plasticizing than sorbitol in the HC/SA films. In the cooperation with water as co-plasticizer (glycerol/water or sorbitol/water), the $T_{\mathrm{g}}$ values of all films were dramatically decreased to $-50{ }^{\circ} \mathrm{C}$ for glycerol/water plasticized films and down to $0{ }^{\circ} \mathrm{C}$ for sorbitol/water plasticized films. The reasonable flexible films could be obtained by the use of either glycerol/water or sorbitol/water as couple plasticizers.
\end{abstract}

\section{Introduction}

In recent years, polysaccharide films have been used to replace petroleum-based polymers owing to their biodegradability, renewability and non-toxicity. Among various kinds of the polysaccharides, chitosan (CS) and sodium alginate (SA) are interesting. CS is obtained from the deacetylation of chitin. Due to the strong antimicrobial activity of CS, many studies relating to the applications of CS based edible films have been reported [1-3]. SA is extracted from brown seaweeds. The main advantage of SA is good film-forming ability, which makes SA widely used as edible films [4-6]. The mixtures from the combination of CS and SA have been studied [7]. With regard to the film forming procedure, CS could not homogeneously blend with SA because they immediately form gel by ionic crosslinking between their structures. As this point, water-soluble hydroxyethylacryl chitosan (HC) was replaced.

Many research have been reported that polysaccharide films are fragile and brittle, which limit their potential for applications [8-9]. In order to overcome these problems, plasticizers are added to provide the suitable ability. Main non-volatile plasticizers are glycerol and sorbitol [10-12]. Apart from glycerol and sorbitol, water is a ubiquitous natural diluent, which can act as a plasticizer. It has been reported that glass transition temperature $\left(T_{g}\right)$

\footnotetext{
$\overline{{ }^{a} \text { Corresponding author: ptreenate@ }}$ hotmail.com
}

of polysaccharide films strongly decreases with increasing water content [13].

It is expected that the new type of edible film can be developed by the effective combination of HC with SA using glycerol/water or sorbitol/water as plasticizers. The aim of this research was to investigate the effects of glycerol/water and sorbitol/water on the plasticization of HC/SA films.

\section{Experimental procedure}

\subsection{Preparation of hydroxyethylacryl chitosan (HC)}

$\mathrm{HC}$ was prepared by referring to the procedure of $\mathrm{P}$. Treenate et al. [14]. Briefly, CS was added into a solution of $1 \% \mathrm{w} / \mathrm{w}$ acetic acid. Hydroxyethylacrylate was then added into the solution. The mixture was reacted at $60{ }^{\circ} \mathrm{C}$ for $48 \mathrm{~h}$. The solution was neutralized and precipitated in acetone to obtain $\mathrm{HC}$.

\subsection{Film preparation}

$\mathrm{HC}$ and SA with varying weight ratios of HC:SA were dissolved in distilled water under continuous stirring at $70{ }^{\circ} \mathrm{C}$. Plasticizers (i.e., glycerol and sorbitol) were 
added at various concentrations $(25-50 \%$ w/w, with respect to dry weight of the polymer). Following the addition of plasticizers, stirring was continued for $24 \mathrm{~h}$. The solutions were then poured into the Petri dishes and dried at $40{ }^{\circ} \mathrm{C}$ to form the films. The obtained films were conditioned at $50 \% \mathrm{RH}$ at $25{ }^{\circ} \mathrm{C}$ for at least $24 \mathrm{~h}$ in a controlled environmental chamber. The samples were characterized by differential scanning calorimetry (DSC) and dynamic mechanical analysis (DMA).

\section{Results and discussion}

\subsection{Miscibility between polymer and plasticizer}

DSC thermograms of pure glycerol (GLY) and pure sorbitol (SOR) show a single endothermic peak at $-78{ }^{\circ} \mathrm{C}$ (Figure 1a) and $0{ }^{\circ} \mathrm{C}$ (Figure $1 \mathrm{~b}$ ), respectively. In the plasticized HC/SA films, there was no phase separation between the polymer and the plasticizer in the films. It could be recommended that the polymer and the plasticizer were miscible for all blend compositions.
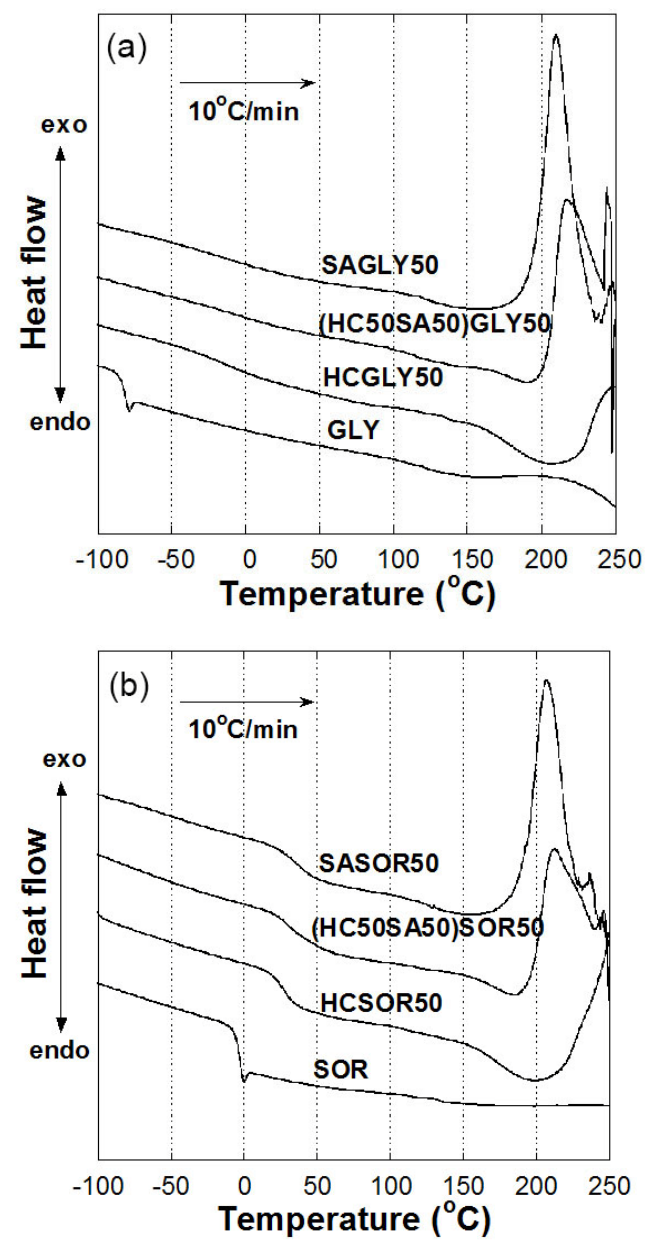

Figure 1. DSC thermograms of (a) glycerol and (b) sorbitol plasticized HC/SA films ( $50 \% \mathrm{w} / \mathrm{w}$ of plasticizer).

\subsection{Effect of plasticizer types on $T_{g}$ of the films}

From Figure 2, the glycerol plasticized HC/SA films show the lower values of $\mathrm{T}_{\mathrm{g}}$ compared to the sorbitol plasticized films. It was suggested that sorbitol did not strongly affect on $T_{g}$ of the films as much as glycerol because sorbitol molecule is relatively bigger than glycerol. In addition, the fact that glycerol, due to its hydrophilic nature, can hold and contain water within the films, while sorbitol acts as a plasticizer with a minimum contribution from water molecules. Therefore, the addition of glycerol led to higher moisture contents resulting in increased plasticizing ability.
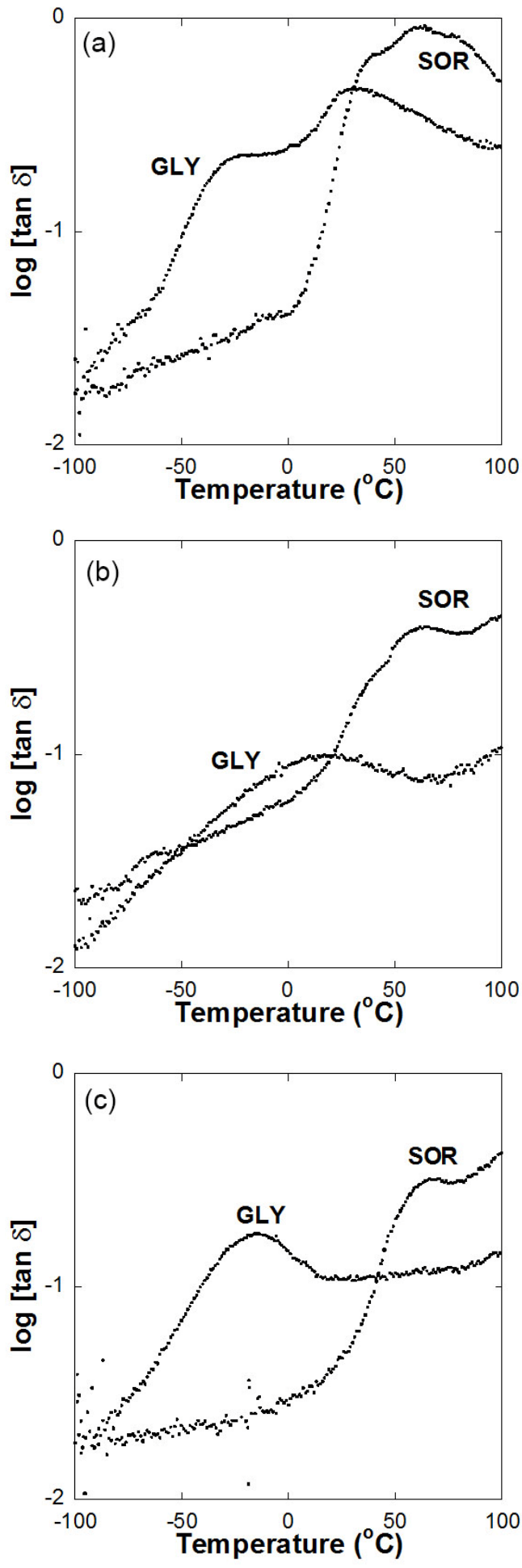

Figure 2. Effect of plasticizer types on $\tan \delta$ of (a) HC, (b) $\mathrm{HC} / \mathrm{SA}$, and (c) SA films as a function of temperature $(50 \%$ $\mathrm{w} / \mathrm{w}$ of plasticizer). 


\subsection{Effect of plasticizer concentration on $T_{g}$ of the films}

From Figure 3, values of $T_{g}$ decrease with increasing plasticizer concentration, which indicates the plasticizing effect of glycerol and sorbitol. Higher plasticizer concentrations led to the change of the physical structure of the films by decreasing the intermolecular forces between the polymer chains, increasing the free volume, and consequently increased the mobility of the polymer chains resulting in the lower values of $\mathrm{T}_{\mathrm{g}}$. In addition, a remarkable reduction of $\mathrm{T}_{\mathrm{g}}$ could be obtained by adding glycerol over $40 \% \mathrm{w} / \mathrm{w}$. For sorbitol plasticized films, although the addition of sorbitol could reduce $T_{g}$, it was still higher than room temperature. Furthermore, the $T_{g}$ values of the plasticized films were higher than $\mathrm{T}_{\mathrm{g}}$ of pure plasticizer $\left(-78^{\circ} \mathrm{C}\right.$ and $\left.0{ }^{\circ} \mathrm{C}\right)$. It was confirmed that there was no phase separation between the polymer and the plasticizer supporting to DSC results.
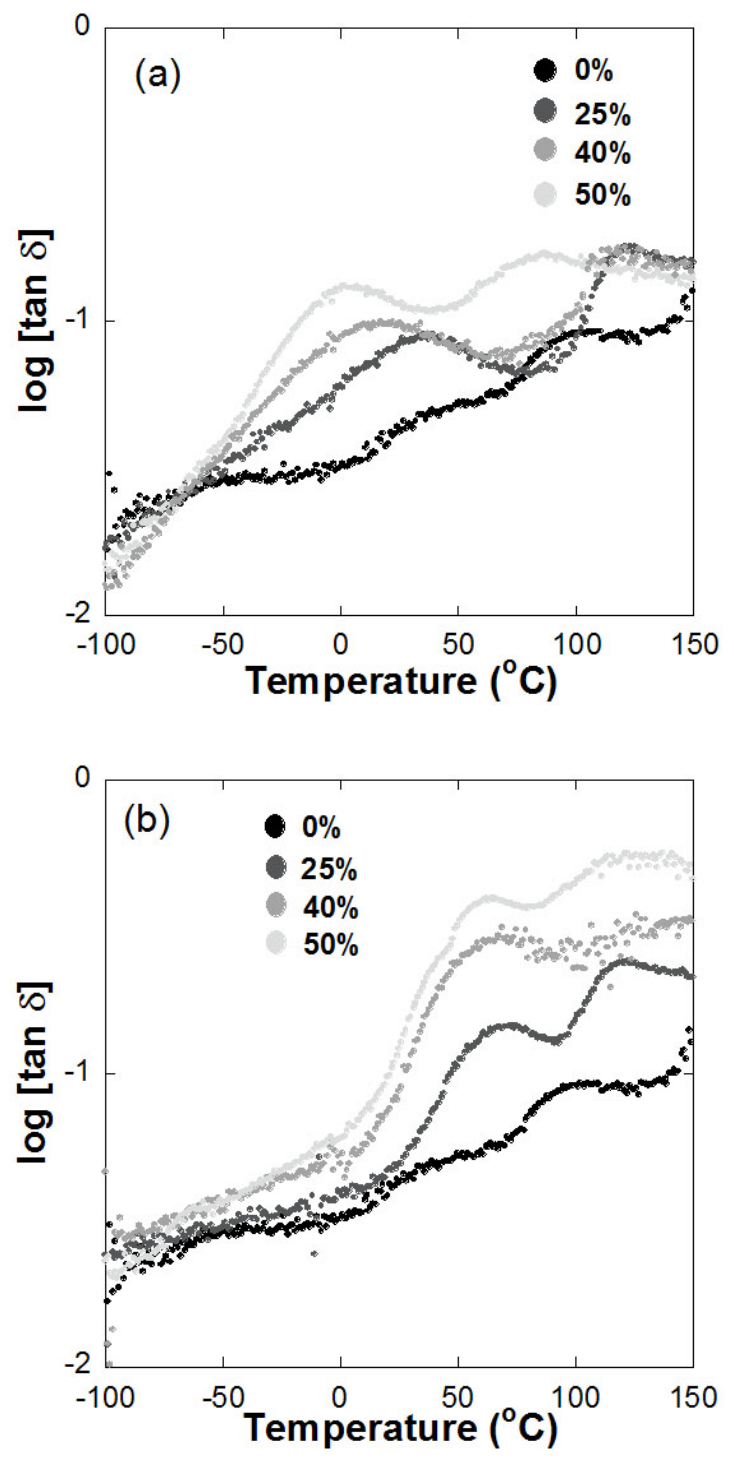

Figure 3. Effect of plasticizer concentrations on tan $\delta$ of (a) glycerol and (b) sorbitol plasticized HC/SA films as a function of temperature.

\subsection{Effect of water on $T_{g}$ of the films}

In the cooperation with water as co-plasticizer (glycerol/water or sorbitol/water), the $\mathrm{T}_{\mathrm{g}}$ values of $25 \%$ $\mathrm{w} / \mathrm{w}$ plasticizer plasticized films were dramatically decreased to $-50{ }^{\circ} \mathrm{C}$ for glycerol/water plasticized films and down to $0{ }^{\circ} \mathrm{C}$ for sorbitol/water plasticized films. When increasing water content, water molecules would solvate the plasticizer molecules that might enhance the plasticizing ability of those plasticizers. Therefore, it could be seen that the reasonable flexible films could be obtained by the use of either glycerol/water or sorbitol/water as couple plasticizers.
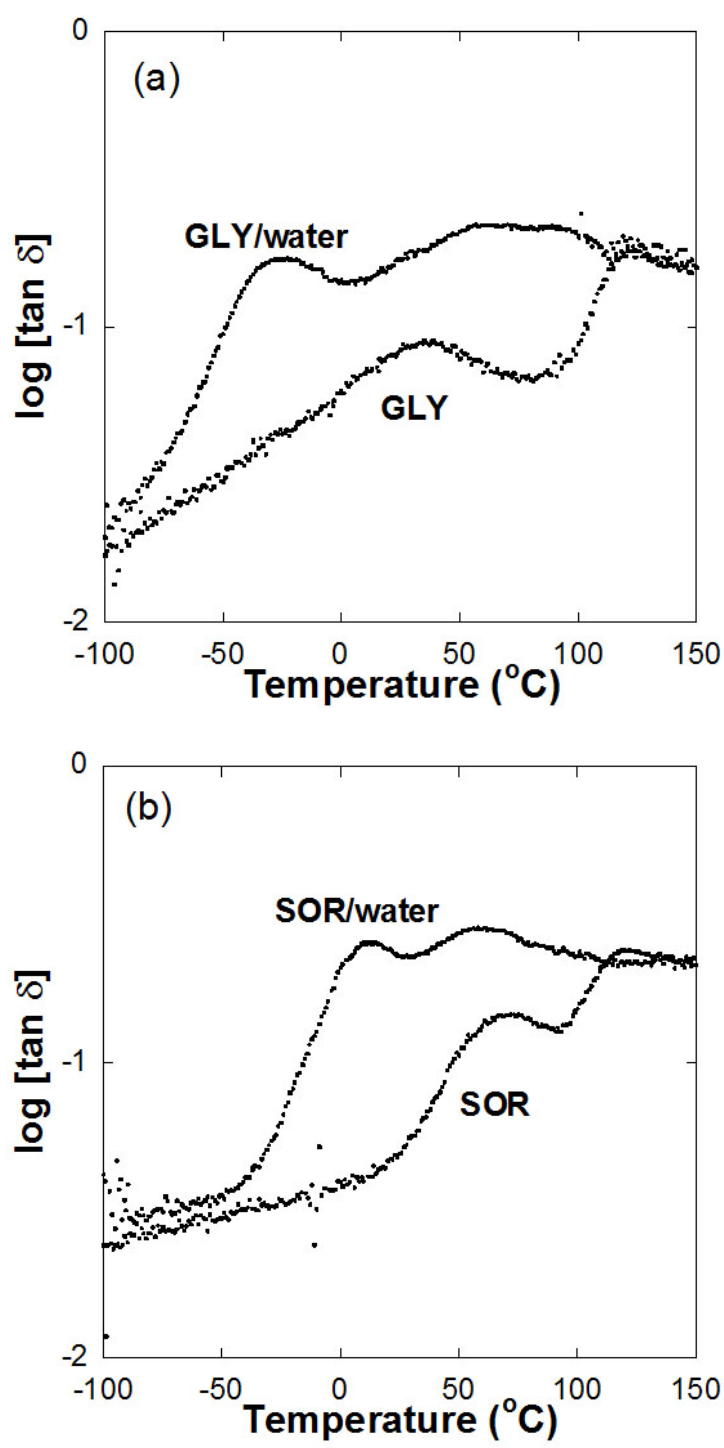

Figure 4. Effect of water on tan $\delta$ of (a) glycerol and (b) sorbitol plasticized films as a function of temperature $(25 \% \mathrm{w} / \mathrm{w}$ of plasticizer).

\section{Conclusion}

The new type of edible film could be developed by the combination of $\mathrm{HC}$ with SA using glycerol/water or sorbitol/water as plasticizers. DSC results showed the 
miscibility of polymer and plasticizers (glycerol and sorbitol) for all blend compositions. Glycerol strongly affected $T_{g}$ of the films as compared with sorbitol. The use of co-plasticizer (glycerol/water or sorbitol/water) showed higher efficiency plasticizing ability. The comprehensive results of this study suggested their potential in the application of edible films.

\section{References}

1. W. Thakhiew, S. Devahastin, S. Soponronnarit, J. Food Eng. 99, 216-224 (2010)

2. J.F. Fundo, R. Fernandes, P.M. Almeida, A. Carvalho, G. Feio, C.L.M. Silva, M.A.C. Quintas, Food Chem. 144, 2-8 (2014)

3. E. Genskowsky, L.A. Puente, J.A. Pérez-Álvarez, J. Fernandez-Lopez, L.A. Muňoz, M. Viuda-Martos, LWT Food Sci. Technol. 64, 1057-1062 (2015)

4. M.A. Rojas-Graü, R.J. Avena-Bustillos, C. Olsen, M. Friedman, P.R. Henika, O. Martín-Belloso, Z. Pan, T.H. McHugh, J. Food Eng. 81, 634-641 (2007)
5. S. Galus, A. Lenart, J. Food Eng. 115, 459-465 (2013)

6. Q. Xiao, Q. Tong, Food Res. Int. 54, 1605-1612 (2013)

7. I.A. Vázquez, J.J.C. Pérez, G.C. Domínguez, E.T. Rojas, V.G. Febles, A.M. Rivas, G.F.G. López, Carbohydr. Polym. 87, 289-299 (2012)

8. M. Huang, J. Yu, X. Ma, Polym. Degrad. Stab. 90, 501-507 (2005)

9. R.N. Tharanathan, Trends Food Sci. Technol. 14, 7178. (2003)

10. M. Liu, Y. Zhou, Y. Zhang, C. Yu, S. Cao, Int. J. Biol. Macromol. 70, 340-346 (2014)

11. M.G.A. Vieira, M.A. da Silva, L.O. dos Santos, M.M. Beppu, Eur. Polym. J. 47, 254-263 (2011)

12. M. Avella, E.D. Pace, B. Immirzi, G. Impallomeni, M. Malinconico, G. Santagata, Carbohydr. Polym. 69, 503-511 (2007)

13. E.M. Teixeira, A.L. da Róz, A.J.F. Carvalho, A.A.S. Curvelo, Carbohydr. Polym. 69, 619-624 (2007)

14. P. Treenate, P. Monvisade, M. Yamaguchi, J. Polym. Res. 21, 1-12 (2014) 